\title{
High-fat, sucrose diet impairs geometrical and mechanical properties of cortical bone in mice
}

\author{
Caeley Lorincz ${ }^{1}$, Raylene A. Reimer ${ }^{1}$, Steven K. Boyd ${ }^{1,2}$ and Ronald F. Zernicke ${ }^{1,2,3,4 *}$ \\ ${ }^{1}$ Faculty of Kinesiology, Human Performance Laboratory, Roger Jackson Centre for Health and Wellness Research, University of \\ Calgary, 2500 University Drive NW, Calgary, AB, Canada T2N $1 N 4$ \\ ${ }^{2}$ Schulich School of Engineering, University of Calgary, 2500 University Drive NW, Calgary, AB, Canada T2N 1N4 \\ ${ }^{3}$ McCaig Centre for Joint Injury and Arthritis Research, University of Calgary, 3300 Hospital Drive NW, Calgary, AB, Canada \\ T2N $4 N 1$ \\ ${ }^{4}$ Departments of Orthopaedic Surgery and Biomedical Engineering, School of Kinesiology, University of Michigan, 24 Frank Lloyd \\ Wright Drive, Lobby A, Ann Arbor, MI 48105, USA
}

(Received 17 April 2009 - Revised 27 October 2009 - Accepted 28 October 2009 - First published online 8 December 2009)

\begin{abstract}
Exposure to diets high in fat and sucrose can induce hyperinsulinaemia, affect $\mathrm{Ca}$ and $\mathrm{Mg}$ metabolism, and alter bone mineralisation and mechanical properties. The present study assessed morphological and mechanical changes in a murine model exposed to a high-fat/sucrose (HFS) diet, as well as corresponding molecular and endocrine markers of bone turnover. Female C57BL/6 mice (aged 9 weeks) consumed either a low-fat, complex carbohydrate diet or an HFS diet for 10 weeks. At the end of the 10 weeks, serum was collected for biochemical analysis. Tibiae from half the mice ( $n$ 15) were randomly selected to be micro-computed tomography scanned and tested to failure in cantilever bending, while the remaining half were prepared for real-time PCR analysis. Serum tartrate-resistant acid phosphatase was significantly elevated in HFS mice, while osteocalcin remained unchanged. Both body mass and percentage body fat were greater in mice fed HFS diet. After adjusting for body mass, tibial structural and morphological properties were adversely affected in the HFS cohort. Cortical thickness, cross-sectional area, and load at maximum were all significantly lower in mice fed HFS diet. Receptor activator of nuclear factor $\kappa \beta$ ligand (RANKL) mRNA was significantly upregulated in HFS mice, but osteoprotegerin/RANKL mRNA ratio remained unchanged between cohorts. Moreover, cyclo-oxygenase- 2 mRNA tended to be increased in HFS. Thus, ingestion of an HFS diet had a significant adverse effect on mouse bone morphology and mechanics, and these effects were likely due to elevated osteoclast activity associated with the inflammatory state of obesity, and not necessarily osteoclast recruitment/ proliferation.
\end{abstract}

Cortical bone: High-fat/sucrose diet: Biomechanics: C57BL/6 mice

The changing face of disease aetiology over the past century has brought to the forefront the need to examine the environmental or modifiable risk factors that have influenced the epidemic of chronic disease afflicting a majority of the Western world. Nutritional status is a readily modifiable risk factor linked to numerous chronic conditions, including CHD, cancer, obesity, diabetes and osteoporosis ${ }^{(1,2)}$. Nonetheless, despite the prevalence of research linking poor dietary choices to chronic disease status, the nutritional patterns presently dominating most Western nations continue to be high in saturated fats, $\mathrm{Na}$ and refined carbohydrates from sugars, cereals and dairy products, and low in fruits, vegetables and lean protein $^{(3)}$.

Considerable effort has focused on discovering the underlying nutritional factors that predispose an individual to osteopenia or osteoporosis and subsequent fracture ${ }^{(4)}$. Much research has concentrated on the role of $\mathrm{Ca}$ and vitamin $\mathrm{D}$ metabolites influencing bone morphology and mechanics; however, macronutrients such as fat, protein and carbohydrate also play a vital role in bone health ${ }^{(5)}$. Considered independently, consumption of diets composed of large amounts of saturated fat has been documented to cause the formation of insoluble soap complexes with ingested $\mathrm{Ca}$ in the gut, thus preventing $\mathrm{Ca}$ absorption ${ }^{(6-8)}$. Additionally, ingestion of sucrose alone encourages $\mathrm{Ca}$ excretion in the urine or hypercalciuria $^{(9-12)}$. While earlier reports ${ }^{(4,13-17)}$ suggest that diets that include both high-saturated fat/sucrose (HFS) have a profound effect on skeletal structural integrity, the underlying mechanisms remain incompletely understood.

HFS diets fed to young, rapidly growing rats produced deleterious effects on normal bone morphology and structural properties of tibia and metatarsus ${ }^{(14)}$, femoral neck ${ }^{(16)}$ and lumbar vertebrae ${ }^{(4,18)}$. Those effects were exacerbated in the femoral neck and lumbar vertebrae of rats fed an HFS diet

Abbreviations: COX-2, cyclo-oxygenase-2; Ct.Th, cortical thickness; HFS, high-fat/sucrose; LFCC, low-fat, complex carbohydrate; OPG, osteoprotegerin; RANKL, receptor activator of nuclear factor $\kappa \beta$ ligand; TRAP, tartrate-resistant acid phosphatase.

* Corresponding author: Professor Ronald F. Zernicke, fax +1 734930 7402, email zernicke@umich.edu 
long term, suggesting that the skeleton did not positively adapt to this nutritional diet regimen to mitigate osteopenia over the lifespan ${ }^{(15)}$.

To date, however, reports examining the effects of an HFS diet on bone mechanical properties and morphology have not investigated the concurrent effect on expression of regulators of osteoclast function associated with chronic consumption. Therefore, the objective of the present study was to investigate the effects of consuming an HFS diet on bone mechanical and morphological properties, in conjunction with molecular and biochemical markers of bone turnover and homoeostasis in a skeletally immature murine model.

\section{Experimental methods}

\section{Animal model}

Sixty inbred female C57BL/6 mice (6 weeks) were obtained from Charles River Canada (LaSalle, QC, Canada). All mice were allowed free cage activity for 13 weeks (3 weeks for acclimatisation and 10 weeks for diet consumption), housed in a pathogen-free environment located within the Single Mouse Barrier Unit at the Heritage Medical Research Building (Calgary, AB, Canada) until euthanisation at the age of 19 weeks. Each cage $\left(44 \times 25 \times 16 \mathrm{~cm}^{3}\right)$ housed five mice. The light-dark cycle was $12: 12$ from 07.00 to 19.00 hours; ambient temperature varied between 21 and $25^{\circ} \mathrm{C}$, and relative humidity was $60 \%$. All experimental procedures involving animals were approved by the University of Calgary Animal Care Committee and conformed to the Guide for the Care and Use of Laboratory Animals.

\section{Dietary regimen}

After 3 weeks of a baseline period, mice (approximately 20 g) were randomly assigned to one of two dietary groupings: a HFS diet group ( $n$ 30) or a low-fat, complex carbohydrate (LFCC) diet group ( $n$ 30). Both diets were custom-prepared (Teklad Corporation, Madison, WI, USA; TD.85 080: LFCC diet, TD.83 402: HFS diet; Table 1) and were selected based on prior research ${ }^{(19,20,21)}$. Diets were designed to differ in energy density in order to address differences in bone mechanical

Table 1. Diet composition

\begin{tabular}{lcc}
\hline Ingredient $(\mathrm{g} / \mathrm{kg})$ & LFCC diet & HFS diet \\
\hline Casein & $247 \cdot 8$ & 250.0 \\
DL-Met & 2.5 & 2.5 \\
Sucrose & 0.0 & 472.5 \\
Maize starch & 649.0 & 0.0 \\
Lard & 17.7 & 190.0 \\
Maize oil & $18 \cdot 0$ & 20.0 \\
Cellulose (fibre) & 20.0 & 20.0 \\
Mineral mix (catalogue no. 170915) & 35.0 & 35.0 \\
Vitamin mix (catalogue no. 40 060) & 10.0 & 10.0 \\
Energy content (kJ/g) & 15.06 & 20.08 \\
\hline
\end{tabular}

LFCC, low-fat, complex carbohydrate; HFS, high-fat/sucrose. Diets were custom prepared by Teklad Corporation (Madison, WI, USA). Energy composition of the LFCC $v$. HFS diets, respectively, were: complex carbohydrate $(68.0 \mathrm{v} .0 \%)$, sucrose ( $0 \mathrm{v} .39 .5 \%)$, fat $(6 \mathrm{v} .39 .5 \%)$ and protein (26 v. $21 \%)$. properties between a high-energy-dense diet (HFS) and a lowenergy-dense diet (LFCC). Ca (17.5 g/kg diet) and vitamin D (19 824 units $/ \mathrm{kg}$ diet) contents were similar between diets. Lard was used in the present study to increase saturated fat content and had the following fatty acid composition: oleic acid, $46 \%$; palmitic acid, $26.5 \%$; stearic acid, $12.5 \%$; linoleic acid, $12 \%$; linolenic acid, $1.5 \%$; myristic acid, $1.5 \%$. Maize oil was composed of: oleic acid, $30.7 \%$; palmitic acid, $12.1 \%$; stearic acid, $2.2 \%$; linoleic acid, $54 \%$; linolenic acid, $1 \%$. Food and water were provided ad libitum. Mice remained on their respective diets for 10 weeks as per previous study protocols ${ }^{(4,13,14,17)}$.

\section{Blood collection}

On the day of euthanisation, mice were anaesthetised with isoflurane, and blood sampled via cardiac puncture. Blood was collected in standard serum vacutainers (Becton Dickinson Vacutainer systems, Franklin Lakes, NJ, USA) and centrifuged for $10 \mathrm{~min}$ at $1500 \mathrm{~g}$. Serum was stored at $-80^{\circ} \mathrm{C}$ for subsequent analysis. Mice were euthanised via cervical dislocation.

\section{Biochemical analysis}

As a measure of bone formation, serum concentrations of osteocalcin were determined by a sandwich ELISA (Biomedical Technologies Inc., Stoughton, MA, USA) with a sensitivity of $1 \mathrm{ng} / \mathrm{ml}$. The intra-assay CV was $8.0 \%$. Serum tartrateresistant acid phosphatase (TRAP) activity was measured by ELISA (Mouse TRAP Assay, SBA Sciences, Turku, Finland) as a measure of bone resorption. The sensitivity of this measurement was $0 \cdot 1 \mathrm{U} / \mathrm{l}$, and the intra-assay $\mathrm{CV}$ was $4.8 \%$. As a control outcome variable and to ensure healthy kidney function, intact parathyroid hormone concentration in serum was measured by an ELISA (Immutopics, San Clemente, CA, USA). The sensitivity of the measurement was $3 \mathrm{pg} / \mathrm{ml}$. The intra-assay CV was $2.8 \%$. Due to the small volume of serum available per mouse, 1, 25-dihydroxyvitamin $\mathrm{D}_{3}$ was difficult to measure. As such, reflection of total body vitamin $\mathrm{D}$ status among the mice was tested via measurement of serum 25-hydroxyvitamin $\mathrm{D}_{3}\left(25-\mathrm{OH} \text { vitamin } \mathrm{D}_{3}\right)^{(22)}$. The $25-\mathrm{OH}$ vitamin $\mathrm{D}_{3}$ was measured by an RIA (Diasorin, Still Water, MN, USA). Sensitivity of the assay was $1.5 \mathrm{ng} / \mathrm{ml}$, and the intra-assay $\mathrm{CV}$ was $3.5 \%$.

\section{Tissue collection and storage}

Upon euthanisation, half of the mice from each dietary cohort (LFCC and HFS) were randomly assigned to have their tibiae used for real-time PCR analysis $(\mathrm{LFCC}=15$; HFS $=15$ ) or for biomechanical and morphological indices of bone adaptation $(\mathrm{LFCC}=15$; HFS $=15)$. The right and left tibiae of all mice were disarticulated at the knee and ankle joints, and cleaned of all non-osseous tissue. For mice allocated to realtime PCR analysis, cleaned tibiae were immediately placed in labelled $1.5 \mathrm{ml}$ tubes (Fischer Scientific Ltd, Nepean, ON, Canada), snap frozen in liquid nitrogen and stored at $-80^{\circ} \mathrm{C}$ until further analysis. For mice allocated to biomechanical and morphological testing, tibiae were cleaned and wrapped in gauze soaked in saline $(50 \mathrm{~mm}$ potassium phosphate 
buffer solution, $\mathrm{pH} 7 \cdot 4$; PBS), hermetically sealed and stored at $-20^{\circ} \mathrm{C}$ until further analysis.

\section{Microstructural imaging}

Tibiae allocated to the biomechanical and morphological grouping were analysed by micro-computed tomography. Frozen tibiae were thawed at room temperature for at least an hour before scanning. Proximal right tibiae were immobilised in a micro-computed tomography jig hand constructed from foam. The jig was formed in the shape of a revolver bullet chamber to hold five tibiae for analysis at one time. Bones were aligned at the level of the tibial plateau, using the scout view, within the jig to ensure similar scanning regions. Scans were performed (vivaCT 40, Scanco Medical AG, Bruettisellen, Switzerland) with an effective energy of $55 \mathrm{kVp}$ and $109 \mathrm{~mA}$, integration time of $200 \mathrm{~ms}$, and a nominal isotropic resolution of $10.5 \mu \mathrm{m}$.

Four-hundred and twenty-two slices were captured, equivalent to approximately $4.4 \mathrm{~mm}$ of the tibial mid-shaft length, measured proximal to the tibia-fibular junction. Bone tissue was identified within the image using semi-automated contouring. Before evaluation, bone images were Gaussian filtered (support of 2 and standard deviation of 1.2) and mineralised tissue was extracted using a global threshold $(22.4 \%$ of the maximal image value). All image processing was performed by the Image Processing Library Software (Scanco Medical AG). Tibial images were evaluated for cortical thickness (Ct.Th), cortical cross-sectional area and cortical bone mineral density. Upon completion of each scan, tibiae were saturated in PBS, hermetically sealed and returned to $-20^{\circ} \mathrm{C}$ for storage until mechanical testing.

\section{Mechanical testing: three-point bending}

Tibial geometry permits more stable and repeatable placement of the diaphyseal shaft on the loading span than the femoral diaphysis, which is more circular in cross section ${ }^{(23)}$. On the day of mechanical testing, tibiae were thawed in $22^{\circ} \mathrm{C}$ PBS for at least $1 \mathrm{~h}$. Tibial length was measured $( \pm 0.01 \mathrm{~mm})$ using digital callipers (Model 14-648-17, Fisher Scientific, Ottawa, ON, Canada). When each specimen was thawed, the round-surfaced cross head probe of a servo-controlled electromechanical testing system (Model 1122, Instron Corp., Canton, MA, USA) contacted the medial tibial surface at its longitudinal midpoint, between a $6 \mathrm{~mm}$ loading $\operatorname{span}^{(2,24,25)}$. Testing order was stratified based on dietary cohort, and load was applied at $0 \cdot 17 \mathrm{~mm} / \mathrm{s}^{(1,25)}$ with a $50 \mathrm{~kg}$ compression load cell (Instron 2511-203; Instron Corp., Canton, MA, USA) until failure. Load-deformation curves were digitised $(200 \mathrm{~Hz}$; Dataq Instruments, DI-730 Series, Akron, OH, USA), and structural properties such as tibial maximal load, load at proportional limit and energy to failure were determined. Material properties such as stress at proportional limit, stress at maximal load and flexural rigidity were calculated $^{(26,27)}$.

\section{Real-time PCR}

Tibiae designated for real-time PCR were removed from $-80^{\circ} \mathrm{C}$ and reduced to powder form using a liquid nitrogen-cooled Braun Mikro-Dismembrator Vessel (B. Braun Biotech International, Allentown, PA, USA). Total RNA was extracted from samples using TRIzol Reagent (Invitrogen, Carlsbad, CA, USA). RNA was quantified using Ribogreen, and reverse transcription was performed using the Omniscript RT Kit (Qiagen, Mississauga, ON, Canada) ${ }^{(28)}$. The same number of samples for each cDNA was analysed to prevent bias in the results. Each sample was analysed in triplicate in a total reaction volume of $25 \mu$ l consisting of $5 \mu$ dilute cDNA (1:10) and $20 \mu \mathrm{l}$ Master Mix. The Master Mix contained $2.5 \mu \mathrm{l}$ of $10 \times$ PCR buffer, $1.5 \mu \mathrm{l}$ of $50 \mathrm{mmol} / \mathrm{l}$ $\mathrm{MgCl}_{2}, 0.05 \mu \mathrm{l}$ of $100 \mathrm{mmol} / \mathrm{l}$ dNTPs, $2.5 \mu \mathrm{l}$ sybergreen (1:5000), 1.0 $\mu$ l fluoroscein (1:10000), 0.2 $\mu 1$ Taq DNA polymerase (Invitrogen) and the required amount of forward and reverse primers. The primer sequences for genes of interest such as receptor activator of nuclear factor $\kappa \beta$ ligand (RANKL), osteoprotegerin (OPG), cyclo-oxygenase-2 (COX-2), cathepsin $\mathrm{K}$ and PPAR $-\gamma$ are available upon request from the investigators. Reactions were run on an iCycler thermal cycler (Bio-Rad, CA, USA) using the following cycling conditions: $95^{\circ} \mathrm{C}$ for $1: 30 \mathrm{~min}$ and 40 cycles at $95^{\circ} \mathrm{C}$ for $25 \mathrm{~s}, 60^{\circ} \mathrm{C}$ for $20 \mathrm{~s}$ and $72^{\circ} \mathrm{C}$ for $20 \mathrm{~s}$. For each experiment, a non-template reaction was included as negative control. Glyceraldehyde-3-phosphate dehydrogenase primers were included in the reaction as internal controls for all genes. The specificity of the PCR was confirmed by melting curves analysis of the products. The threshold cycle values $\left(C_{\mathrm{t}}\right)$ were determined at the same fluorescence threshold line for each gene. $C_{\mathrm{t}}$ values were transformed into fold change. The mRNA expression, measured in arbitrary units, of the target gene relative to the control was determined using the $2^{-C_{\mathrm{t}}} \operatorname{method}^{(29)}$.

\section{Body composition}

Percentage body fat was determined for all mice, and the analysis included the entire carcass (less the lower limbs that had been removed for the aforementioned analyses). Scans of the bodies were performed using micro-CT (XtremeCT, Scanco Medical AG) with settings of $100 \mathrm{~ms}$ integration time and beam energy of $60 \mathrm{kVp}$ and $1 \mathrm{~mA}$ providing a nominal isotropic resolution of $82 \mu \mathrm{m}$. The data were resampled by a factor of 2 due to hardware constraints, and Gaussian filtered (sigma 1.2 and support of 2) to reduce noise. The resulting images were segmented using a custom algorithm that utilised global thresholds to capture the lean and mineralised tissue (61/1000) separately from the entire body mass (24/1000). Subtracting the volume represented by the former output from the latter resulted in the total volumetric body fat from which percentage body fat was determined.

\section{Statistics}

For morphological, mechanical and histological data, differences between LFCC and HFS dietary cohorts were assessed using independent $t$ tests. Statistical significance was corrected for multiple $t$ tests by dividing the experiment-wise $\alpha$-level $(0.05)$ by the number of $t$ tests per variable set. Molecular analysis was completed using a one-way ANOVA. Data are presented as means and standard deviations. Data analysis was performed using SPSS 15.0 for Windows (SPSS Inc., Chicago, IL, USA). 


\section{Results}

\section{Body mass}

Baseline body mass was not significantly different between LFCC and HFS cohorts; however, at the end of the 10-week diet intervention, the average body mass of the HFS cohort was greater than the LFCC cohort by approximately $40 \%$ (35.7 (SD 4.0) v. $25 \cdot 3$ (SD 2.4) g, respectively; $P<0.001$ ). Percentage body fat was also 14.9 (SD 2.0) \% greater in the HFS $v$. LFCC cohort $(P<0 \cdot 001)$. As bone mineral density and bone size are influenced by total body mass ${ }^{(30)}$, and as bone mineral density influences bone strength ${ }^{(31)}$, structural properties presented below were adjusted (divided by grams of body mass) as has been done previously in studies where body weight differs substantially between $\operatorname{groups}^{(15,24,25,32-35)}$.

\section{Biochemical markers of bone turnover}

No significant differences were found between HFS and LFCC groups for serum levels of intact PTH, 25-hydroxyvitamin $\mathrm{D}_{3}$ or osteocalcin. TRAP activity, however, was elevated $30 \%$ in the HFS $v$. the LFCC cohort $(P=0 \cdot 01$; Table 2$)$.

\section{Tibial geometrics and mechanics}

Tibial geometrical parameters included tibial mass, length, mid-shaft cross-sectional area and $\mathrm{Ct}_{\text {. Th }}{ }^{(36)}$. There were no significant differences in geometric, structural or material properties between HFS and LFCC cohorts using data unadjusted for body mass differences (Table 3 ). There were significant differences in total body mass between the two groups, and data were, therefore, normalised to total body mass. This normalisation has been performed by others with interventions that caused marked differences in body mass between groups (i.e. energy restriction, conjugated linoleic acid and genetically lean $v$. obese rodents $\left.{ }^{(24,37)}\right)$. When adjusted for total body mass, relative tibial mid-diaphyseal cortical bone morphology was significantly impaired in the HFS cohort. Consumption of an HFS diet led to a $28 \%$ reduction in Ct.Th compared to mice fed a LFCC diet $(P<0 \cdot 0011$; Fig. 1) as well as a $25 \%$ reduction in mid-shaft cross-sectional area $(P<0.001$; Fig. 1). Relative load at maximum was $23 \%$ lower in the HFS cohort relative to their LFCC counterparts $(P<0.001$; Fig. 1). As well, adjusted energy to failure and flexural rigidity were significantly compromised in HFS mice (Table 4).

Table 2. Serum concentrations of biochemical markers of bone turnover (Mean values and standard deviations, $n 30$ )

\begin{tabular}{|c|c|c|c|c|}
\hline & \multicolumn{2}{|c|}{ LFCC } & \multicolumn{2}{|c|}{ HFS } \\
\hline & Mean & SD & Mean & SD \\
\hline iPTH (ng/l) & $161 \cdot 3$ & 141.4 & $160 \cdot 8$ & $125 \cdot 7$ \\
\hline 25-Hydroxyvitamin $\mathrm{D}_{3}(\mathrm{nmol} / \mathrm{l})$ & $75 \cdot 6$ & $11 \cdot 2$ & $73 \cdot 6$ & 7.5 \\
\hline TRAP $(\mathrm{U} / \mathrm{l})$ & 4.6 & 1.2 & $6 \cdot 0^{*}$ & $1 \cdot 7$ \\
\hline $\mathrm{OC}(\mathrm{nmol} / \mathrm{l})$ & $10 \cdot 4$ & 3.0 & 9.7 & 2.5 \\
\hline
\end{tabular}

$\overline{\text { LFCC, low-fat, complex carbohydrate; HFS, high-fat/sucrose; iPTH, intact parathyroid }}$ hormone; TRAP, tartrate-resistant acid phosphatase; OC, osteocalcin.

* Mean value was significantly different $(P<0.05)$.
Table 3. Tibial cortical geometry and mechanics

(Mean values and standard deviations, $n$ 15)

\begin{tabular}{|c|c|c|c|c|}
\hline & \multicolumn{2}{|c|}{ LFCC } & \multicolumn{2}{|c|}{ HFS } \\
\hline & Mean & SD & Mean & SD \\
\hline \multicolumn{5}{|l|}{ Geometrical } \\
\hline Tibial mass (mg) & $48 \cdot 1$ & $4 \cdot 5$ & $49 \cdot 3^{*}$ & $4 \cdot 2$ \\
\hline Tibial length (mm) & $17 \cdot 7$ & 0.3 & $17 \cdot 7^{\star}$ & 0.3 \\
\hline Cortical thickness $(\mu \mathrm{m})$ & $206 \cdot 11$ & $8 \cdot 1$ & $210 \cdot 0^{*}$ & $13 \cdot 0$ \\
\hline Cross-sectional area $\left(\mathrm{mm}^{2}\right)$ & 0.60 & 0.04 & $0.64^{*}$ & * 0.06 \\
\hline \multicolumn{5}{|l|}{ Structural } \\
\hline Maximal load (N) & $29 \cdot 1$ & $3 \cdot 1$ & $32 \cdot 1^{*}$ & $3 \cdot 8$ \\
\hline Energy to failure ( $\mathrm{N} \mathrm{mm})$ & $12 \cdot 3$ & $4 \cdot 0$ & $9 \cdot 9^{*}$ & $4 \cdot 6$ \\
\hline \multicolumn{5}{|l|}{ Material } \\
\hline Maximal stress (KPa) & $429 \cdot 8$ & $35 \cdot 8$ & $451 \cdot 6$ & $71 \cdot 0$ \\
\hline Flexural rigidity $\left(\mathrm{N} \mathrm{mm}^{2}\right)$ & $851 \cdot 0$ & $126 \cdot 8$ & $827 \cdot 1^{*}$ & $168 \cdot 9$ \\
\hline Bone mineral density $\left(\mathrm{mg} / \mathrm{cm}^{3}\right)$ & $1206 \cdot 1$ & $13 \cdot 1$ & $1197 \cdot 1$ & $16 \cdot 6$ \\
\hline
\end{tabular}

\section{mRNA expression}

Expression of RANKL mRNA was significantly upregulated approximately $36 \%$ in the HFS mice when compared to the LFCC mice $(P<0.05)$, while the slightly elevated expression of OPG mRNA in HFS mice was NS ( $P=0 \cdot 10$; Fig. 2$)$. When considered together, the OPG/RANKL mRNA ratio was not affected by consumption of an HFS diet $(P=0.89$; Fig. 2). COX-2 mRNA expression, although $52 \%$ higher in HFS mice relative to their LFCC counterparts, was NS $(P=0.07$; Fig. 2). In addition, mRNA expression of cathepsin $\mathrm{K}$ and PPAR- $\gamma$ was not significantly different between dietary cohorts.

\section{Discussion}

The HFS diet selected for the present study was based on a plethora of data regarding the ability of this diet to induce obesity in rodents $(19,20,38,39)$, and adversely affect skeletal structural integrity ${ }^{(4,5,14-16)}$. According to the most recent Canadian Community Health Survey, the average Canadian consumes $17 \%$ of energy from protein, $51 \%$ from carbohydrate and $32 \%$ from fat, of which $10 \%$ is saturated fat. However, there is a considerable segment of the population (a substantial subset of whom are adolescent) that habitually consumes fast food, for which the macronutrient composition is much closer to that consumed by our HFS mice $(39.5 \%$ of energy from sucrose and $39.5 \%$ from saturated fat). Fast food comprises a growing portion of food eaten outside the home. Over one-third of North Americans report having eaten fast food on any given day, while $7 \%$ eat fast food daily ${ }^{(40)}$. Nutritional analysis shows fast food to be high in fat, saturated fat, energy density, fructose and glycaemic index, yet poor in fibre, vitamins $\mathrm{A}$ and $\mathrm{C}$ and $\mathrm{Ca}^{(41)}$. Over the past 20 years, sugared beverage intake has increased $70 \%$ in children aged $2-18$ and $83 \%$ in young adults aged $19-36^{(42)}$. Based on these data, the experimental diets examined in skeletally immature female mice in the present study are relevant to a sub-portion of the population - the one considered at greatest risk. 


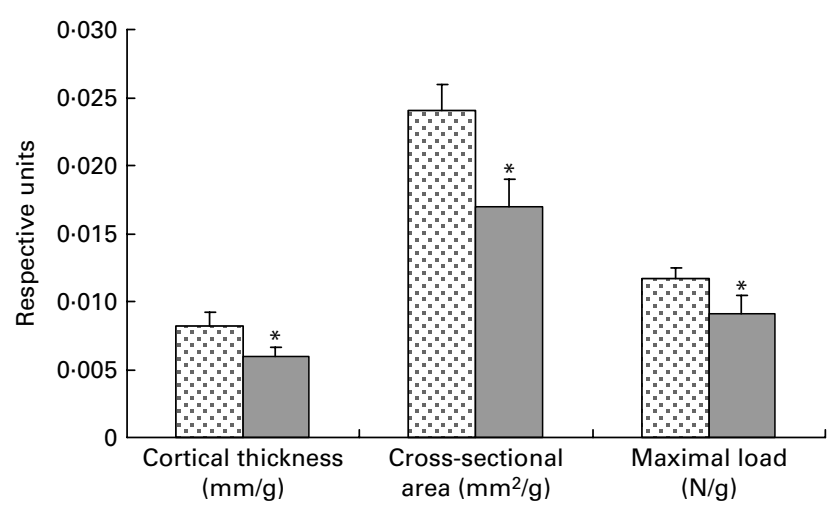

Fig. 1. Low-fat, complex carbohydrate (LFCC) v. high-fat/sucrose (HFS) tibital mid-shaft cortical thickness, mid-shaft cross-sectional area and maximal load. Results are expressed as means and standard deviations ( $n$ 15). Maximal load was reduced by a factor of 100 to fit on the graph. * Mean value was significantly different $(P<0.05)$.. , LFCC; $\square$, HFS.

Morphological findings in female rodents fed a HFS diet $v$. those fed a LFCC diet have been previously reported for either shorter (10 weeks in rats) or longer term ( 2 years) relative duration. Salem et al. ${ }^{(4)}$ reported a decrease of $11 \%$ in cross-sectional area of $\mathrm{L}_{6}$ vertebrae of rats fed an HFS diet for 10 weeks. Moreover, vertebral heights and volumes were substantially diminished in that group ${ }^{(4,15)}$. Conversely, $\mathrm{Li}$ et al. ${ }^{(14)}$ found no significant change in the cross-sectional area of the tibiae of female rats fed an HFS diet for 10 weeks. Our data showing a $25 \%$ reduction in relative tibial cross-sectional area in HFS mice may be related to the animal model and comparative duration of the experiment with respect to the animals' typical lifespan; as previous reports found exacerbation of adverse skeletal effects with prolonged ingestion of HFS diet ${ }^{(15)}$.

In agreement with the observations of a reduced cross-sectional cortical area in the HFS mice, we also observed reduced tibial Ct.Th with HFS. Previous reports noted reduced cortical/ trabecular bone ratios in the femoral neck of rats fed an HFS $\operatorname{diet}^{(9,15)}$, similar to the substantial decrease $(28 \%)$ in the relative tibial diaphyseal $\mathrm{Ct}$.Th observed in the present study. However, as no direct measurements of tibial Ct.Th were examined previously, a direct comparison to those data is not possible.

Table 4. Body mass-adjusted tibial geometry and mechanics (Mean values and standard deviations, $n$ 15)

\begin{tabular}{|c|c|c|c|c|}
\hline & \multicolumn{2}{|c|}{ LFCC } & \multicolumn{2}{|c|}{ HFS } \\
\hline & Mean & SD & Mean & SD \\
\hline \multicolumn{5}{|l|}{ Geometrical } \\
\hline Tibial mass $(\mathrm{mg} / \mathrm{g})$ & 1.9 & $0 \cdot 2$ & $1 \cdot 4^{\star}$ & $0 \cdot 1$ \\
\hline Tibial length $(\mathrm{mm} / \mathrm{g})$ & 0.71 & 0.07 & $0.50^{*}$ & 0.06 \\
\hline Cortical thickness $(\mu \mathrm{m} / \mathrm{g})$ & $8 \cdot 2$ & $1 \cdot 0$ & $5 \cdot 9^{\star}$ & 0.7 \\
\hline Cross-sectional area $\left(\mathrm{mm}^{2} / \mathrm{g}\right)$ & 0.024 & 0.002 & $0 \cdot 017^{*}$ & 0.002 \\
\hline \multicolumn{5}{|l|}{ Structural } \\
\hline Maximal load (N/g) & $1 \cdot 2$ & 0.08 & $0.9^{*}$ & $0 \cdot 13$ \\
\hline Energy to failure $(\mathrm{N} \mathrm{mm} / \mathrm{g})$ & 0.51 & 0.2 & $0.29^{*}$ & 0.2 \\
\hline Flexural rigidity $\left(\mathrm{N} \mathrm{mm}^{2} / \mathrm{g}\right)$ & 34.5 & $5 \cdot 9$ & $23 \cdot 4^{*}$ & $5 \cdot 4$ \\
\hline
\end{tabular}

LFCC, low-fat, complex carbohydrate; HFS, high-fat/sucrose.

${ }^{*}$ Mean values are significantly different when adjusted for body mass $(P<0.001)$
The $23 \%$ decrease in relative tibial maximal load measured in HFS mice in the present study was likely linked to the observed compromised morphological properties of this cohort $^{(14)}$. Previously, Zernicke et al. ${ }^{(15)}$ reported substantial decreases in relative load at maximum in $\mathrm{L}_{6}$ vertebrae and in the femoral neck of HFS rats. The large deficits in maximal load reported in the Zernicke study were likely accounted for by anatomic location, bone type and length of study (2 years $v$. 10 weeks in the present study).

The high-saturated fat content of the current diet also likely contributed to the skeletal decrements observed in HFS mice. Early studies showed that increased levels of saturated fat in the diet impair Ca absorption in the gut via formation of insoluble soaps ${ }^{(6,7,43)}$. As the diet in the present study was high in both sucrose and in SFA such as stearic and palmitic acids, the reductions in the morphological and structural properties observed in the bones of our mice were likely associated with intestinal soap formation as well as altered mineral metabolism, ultimately adversely affecting both $\mathrm{Ca}$ absorption and $\mathrm{Ca}$ retention.

Serum TRAP (a marker of bone resorption ${ }^{(44)}$ ) levels were significantly elevated in HFS mice relative to controls. Given that serum osteocalcin (a marker of bone formation ${ }^{(45)}$ ) levels were not different between cohorts, it appears that ingesting an HFS diet may have disrupted the balance between bone formation and resorption, favouring resorption. Although definitive conclusions cannot be made with the current data alone, greater bone resorption (i.e. osteoclast activity) in the HFS mice supports the present findings of reduced crosssectional area and $\mathrm{Ct}$.Th, leading to structurally compromised skeletal tissue, with potentially elevated resorption at the endosteum and/or the periosteum.

Upregulation of RANKL mRNA in the HFS fed mice may be indicative of increased bone turnover and subsequent loss in this cohort. Whether this is a response to ingesting an HFS diet directly remains to be determined. Elevated OPG mRNA in the HFS cohort, although NS $(P=0 \cdot 10)$, may be due to the increases in leptin circulation associated with inducing obesity in rodents fed an HFS diet. As such, we found no significant differences in the OPG/RANKL mRNA ratio in the HFS $v$. the LFCC mice. These data may suggest that the

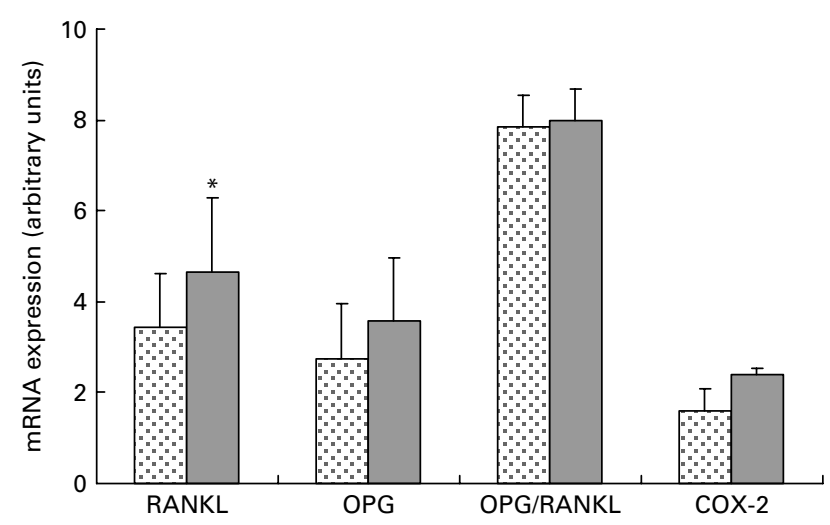

Fig. 2. Low-fat, complex carbohydrate (LFCC) $v$. high-fat/sucrose (HFS) mRNA expression of receptor activator of nuclear factor $\kappa \beta$ ligand (RANKL), osteoprotegerin (OPG), OPG/RANKL and cyclo-oxygenase-2 (COX-2). Results are expressed as means and standard deviations ( $n$ 15). * Mean value was significantly different $(P<0.05)$. : $:$, LFCC; $\square$, HFS. 
elevation in osteoclast activity measured in the serum of the HFS mice was not due to perturbations in the OPG/RANKL axis, but rather to an alternate molecular/biochemical pathway, perhaps associated with the chronic inflammatory state incurred by inducing obesity in the HFS mice.

The role of pro-inflammatory cytokines such as TNF- $\alpha$ and their function in bone resorption may provide an alternate explanation for the increase in TRAP activity measured in the HFS mice in the present study. Increases in TNF- $\alpha$ are associated with negative changes in bone metabolism. It has recently been documented that ingestion of diets high in saturated fat can increase the release of TNF- $\alpha$ from adipose tissue $^{(21,46)}$ and that expression increases with level of obesity $^{(47)}$. As the HFS mice in the present study were largely overweight and ingesting substantial amounts of saturated fat, this cohort likely experienced an elevated level of proinflammatory cytokines, partially accounting for the large elevations in bone resorptive activity, as measured by serum TRAP, but not OPG/RANKL mRNA ratios.

COX-2 mRNA expression was approximately $52 \%$ greater in mice fed an HFS diet. These data agree with a theory of pathologic inflammatory bone resorption created by inducing obesity in the HFS mice as inflammatory mediators, including TNF- $\alpha$ are known stimulators of COX-2 expression ${ }^{(48)}$. During chronic inflammatory states, PG (mainly $\mathrm{PGE}_{2}$ ) can stimulate bone resorption by increasing the amount and functional activity of osteoclasts ${ }^{(49-51)}$. As such, it is possible that an induced inflammatory state in the HFS mice may be associated with the noted elevations in RANKL and COX-2 mRNA. Moreover, this would agree with the findings of compromised morphological and structural indices of strength, in addition to elevated levels of osteoclast activity noted in the serum of the HFS animals.

A notable limitation of the present study was the lack of an 'absolute' control (i.e. a group fed only standard chow or AIN-93 in addition to LFCC and HFS groups). The current diet formulations used a combination of maize oil and lard and more closely resembled the SFA and PUFA profiles of the AIN-76 diet. The most recent rodent dietary recommendations (based on AIN-93 diet) endorse the use of soyabean oil to improve the linolenic acid content. Given that essential fatty acids affect bone metabolism, it cannot be ruled out that there were adverse effects of low $n-3$ fatty acid content in the present study. Another limitation was the lack of food intake data. While it has been established that rodents fed a HFS diet will consume more energy than those fed a diet of normal energy density (similar to our LFCC), we did not have a group of animals consuming a standard chow diet to make direct comparison for the bone parameters measured in the present study.

In summary, the present findings indicated that in the skeletally immature female mouse, ingestion of an HFS diet for 10 weeks markedly reduced tibial structural integrity. Despite the significantly greater body mass of the HFS mice, tibiae were morphologically and structurally inferior to the bones of the LFCC group. Blood data suggested that attenuated bone accretion was likely due to elevated bone resorptive activity in the HFS mice, without affecting the process of bone formation. It appeared that ingestion of a HFS diet did not adversely affect the OPG/RANKL mRNA ratio of young mice, as RANKL and OPG mRNA were elevated to similar extents. However, COX-2 mRNA expression was also elevated, suggesting that the inflammatory state of obesity induced by chronic consumption of a HFS diet may have contributed to resorptive bone loss. Nonetheless, the importance of diet-related changes on skeletal integrity and the significance of consuming a diet rich in saturated fats and refined sugar with respect to bone development and maintenance have potential clinical implications, and, therefore, need to be further investigated to identify key elements associated with diet-related bone loss and to promote non-pharmacological methods of preserving bone mass across a lifespan.

\section{Acknowledgements}

We thank Marjolein Blaauboer, Josh Klinck, Paul Sciore and Kristine Lee for their technical assistance. The authors declare no conflict of interest. C. L. executed all experimental techniques, animal handling, analysis of structural, geometrical and haematological data, and drafted the manuscript. R. A. R. analysed molecular data and edited the manuscript. S. K. B. analysed scanning/image data and edited the manuscript. R. F. Z. obtained funding for the study, interpreted data and edited the manuscript. The present study was supported by the Natural Science and Engineering Research Council of Canada, the Canadian Institutes for Health Research, the Alberta Heritage Foundation for Medical Research and the Wood Professorship for Joint Injury Research.

\section{References}

1. El-Sohemy A (2007) Nutrigenetics. Forum Nutr 60, 25-30.

2. Desiere F (2004) Towards a systems biology understanding of human health: interplay between genotype, environment and nutrition. Biotechnol Annu Rev 10, 51-84.

3. Eaton SB (2000) Paleolithic vs. modern diets-selected pathophysiological implications. Eur J Nutr 39, 67-70.

4. Salem GJ, Zernicke RF \& Barnard RJ (1992) Diet-related changes in mechanical properties of rat vertebrae. Am J Physiol 262 (2 Pt 2), R318-R321.

5. Wohl GR, Loehrke L, Watkins BA, et al. (1998) Effects of high-fat diet on mature bone mineral content, structure, and mechanical properties. Calcif Tissue Int 63, 74-79.

6. French CE (1942) The interrelation of calcium and fat utilization in the growing albino rat. J Nutr 23, 375-384.

7. Tadayyon B \& Lutwak L (1969) Interrelationship of triglycerides with calcium, magnesium and phosphorus in the rat. J Nutr 97, 246-254.

8. Atteh JO \& Leeson S (1984) Effects of dietary saturated or unsaturated fatty acids and calcium levels on performance and mineral metabolism of broiler chicks. Poult Sci 63, 2252-2260.

9. Holl MG \& Allen LH (1987) Sucrose ingestion, insulin response and mineral metabolism in humans. J Nutr 117, 1229-1233.

10. Wood RJ \& Allen LH (1983) Evidence for insulin involvement in arginine- and glucose-induced hypercalciuria in the rat. J Nutr 113, 1561-1567.

11. Tjaderhane L \& Larmas M (1998) A high sucrose diet decreases the mechanical strength of bones in growing rats. J Nutr 128, 1807-1810.

12. Lemann J Jr, Lennon EJ, Piering WR, et al. (1970) Evidence that glucose ingestion inhibits net renal tubular reabsorption of calcium and magnesium in man. J Lab Clin Med 75, $578-585$.

13. Grimditch GK, Barnard RJ, Hendricks L, et al. (1988) Peripheral insulin sensitivity as modified by diet and exercise training. Am J Clin Nutr 48, 38-43. 
14. Li KC, Zernicke RF, Barnard RJ, et al. (1990) Effects of a high fat-sucrose diet on cortical bone morphology and biomechanics. Calcif Tissue Int 47, 308-313.

15. Zernicke RF, Salem GJ, Barnard RJ, et al. (1995) Long-term, high-fat-sucrose diet alters rat femoral neck and vertebral morphology, bone mineral content, and mechanical properties. Bone 16, 25-31.

16. Hou JC, Zernicke RF \& Barnard RJ (1990) High-fat-sucrose diet effects on femoral neck geometry and biomechanics. Clin Biomech 5, 162-168.

17. Grimditch GK, Barnard RJ, Sternlicht E, et al. (1987) Effect of diet on insulin binding and glucose transport in rat sarcolemmal vesicles. Am J Physiol 252 (3 Pt 1), E420-E425.

18. LaMothe JM \& Zernicke RF (2004) Rest insertion combined with high-frequency loading enhances osteogenesis. J Appl Physiol 96, 1788-1793.

19. Levin BE, Dunn-Meynell AA, Balkan B, et al. (1997) Selective breeding for diet-induced obesity and resistance in SpragueDawley rats. Am J Physiol 273 (2 Pt 2), R725-R730.

20. West DB, Boozer CN, Moody DL, et al. (1992) Dietary obesity in nine inbred mouse strains. Am J Physiol 262 (6 Pt 2), R1025-R1032.

21. Kern PA, Saghizadeh M, Ong JM, et al. (1995) The expression of tumor necrosis factor in human adipose tissue. Regulation by obesity, weight loss, and relationship to lipoprotein lipase. J Clin Invest 95, 2111-2119.

22. Holick MF (2004) Sunlight and vitamin D for bone health and prevention of autoimmune diseases, cancers, and cardiovascular disease. Am J Clin Nutr 80, Suppl. 6, 1678S-1688S.

23. LaMothe JM, Hepple RT \& Zernicke RF (2003) Selected contribution: Bone adaptation with aging and long-term caloric restriction in Fischer $344 \times$ Brown-Norway F1-hybrid rats. J Appl Physiol 95, 1739-1745.

24. Lambert J, Lamothe JM, Zernicke RF, et al. (2005) Dietary restriction does not adversely affect bone geometry and mechanics in rapidly growing male Wistar rats. Pediatr Res 57, $227-231$

25. Jurimae J, Jurimae T, Leppik A, et al. (2008) The influence of ghrelin, adiponectin, and leptin on bone mineral density in healthy postmenopausal women. J Bone Miner Metab 26, $618-623$

26. Akhter MP, Iwaniec UT, Covey MA, et al. (2000) Genetic variations in bone density, histomorphometry, and strength in mice. Calcif Tissue Int 67, 337-344.

27. Zernicke RF, Vailas AC, Grindeland RE, et al. (1990) Interactive effects of nutrition, environment, and rat-strain on cortical and vertebral bone geometry and biomechanics. Aviat Space Environ Med 61, 640-647.

28. Reno C, Marchuk L, Sciore P, et al. (1997) Rapid isolation of total RNA from small samples of hypocellular, dense connective tissues. Biotechniques 22, 1082-1086.

29. Maurer AD, Chen Q, McPherson C, et al. (2009) Changes in satiety hormones and expression of genes involved in glucose and lipid metabolism in rats weaned onto diets high in fibre or protein reflect susceptibility to increased fat mass in adulthood. J Physiol 587 Pt 3, 679-691.

30. Blain H, Vuillemin A, Guillemin F, et al. (2002) Serum leptin level is a predictor of bone mineral density in postmenopausal women. J Clin Endocrinol Metab 87, 1030-1035.

31. Gatti D, Sartori E, Braga V, et al. (2001) Radial bending breaking resistance derived by densitometric evaluation predicts femoral neck fracture. Osteoporos Int 12, 864-869.
32. Melton LJ 3rd, Riggs BL, Leibson CL, et al. (2008) A bone structural basis for fracture risk in diabetes. J Clin Endocrinol Metab 93, 4804-4809.

33. Adami S, Gatti D, Viapiana O, et al. (2008) Physical activity and bone turnover markers: a cross-sectional and a longitudinal study. Calcif Tissue Int 83, 388-392.

34. Kaptoge S, Dalzell N, Loveridge N, et al. (2003) Effects of gender, anthropometric variables, and aging on the evolution of hip strength in men and women aged over 65 . Bone 32, 561-570.

35. Petit MA, Beck TJ, Shults J, et al. (2005) Proximal femur bone geometry is appropriately adapted to lean mass in overweight children and adolescents. Bone 36, 568-576.

36. Turner CH \& Burr DB (1993) Basic biomechanical measurements of bone: a tutorial. Bone 14, 595-608.

37. Burr LL, Taylor CG \& Weiler HA (2006) Dietary conjugated linoleic acid does not adversely affect bone mass in obese fa/fa or lean Zucker rats. Exp Biol Med 231, 1602-1609.

38. Levin BE, Triscari J, Hogan S, et al. (1987) Resistance to dietinduced obesity: food intake, pancreatic sympathetic tone, and insulin. Am J Physiol 252 (3 Pt 2), R471-R478.

39. Levin BE, Triscari J \& Sullivan AC (1986) Metabolic features of diet-induced obesity without hyperphagia in young rats. Am J Physiol 251 (3 Pt 2), R433-R440.

40. USDA (1997) Continuing Survey of Food Intakes by Individuals, 1994-1996. In: US Department of Agriculture, ERS, editor. US Department of Agriculture, Economic Research Service: Washington, DC.

41. Guthrie JF, Lin BH \& Frazao E (2002) Role of food prepared away from home in the American diet, 1977-78 versus 1994-96: changes and consequences. J Nutr Educ Behav 34, $140-150$.

42. Nielsen SJ, Siega-Riz AM \& Popkin BM (2002) Trends in energy intake in U.S. between 1977 and 1996: similar shifts seen across age groups. Obes Res 10, 370-378.

43. Bengner U, Johnell O \& Redlund-Johnell I (1988) Changes in incidence and prevalence of vertebral fractures during 30 years. Calcif Tissue Int 42, 293-296.

44. Halleen JM, Alatalo SL, Suominen H, et al. (2000) Tartrateresistant acid phosphatase 5b: a novel serum marker of bone resorption. J Bone Miner Res 15, 1337-1345.

45. Calvo MS, Eyre DR \& Gundberg CM (1996) Molecular basis and clinical application of biological markers of bone turnover. Endocr Rev 17, 333-368.

46. Morin CL, Eckel RH, Marcel T, et al. (1997) High fat diets elevate adipose tissue-derived tumor necrosis factor-alpha activity. Endocrinology 138, 4665-4671.

47. Hotamisligil GS, Arner P, Caro JF, et al. (1995) Increased adipose tissue expression of tumor necrosis factor-alpha in human obesity and insulin resistance. J Clin Invest 95, 2409-2415.

48. Coon D, Gulati A, Cowan C, et al. (2007) The role of cyclooxygenase-2 (COX-2) in inflammatory bone resorption. $J$ Endo $\mathbf{3 3}$, $432-436$.

49. Raisz LG (2001) Potential impact of selective cyclooxygenase-2 inhibitors on bone metabolism in health and disease. Am J Med 110, Suppl. 3A, 43S-45S.

50. Fracon RN, Teofilo JM, Satin RB, et al. (2008) Prostaglandins and bone: potential risks and benefits related to the use of nonsteroidal anti-inflammatory drugs in clinical dentistry. $J$ Oral Sci 50, 247-252.

51. Okada Y, Pilbeam C, Raisz L, et al. (2003) Role of cyclooxygenase-2 in bone resorption. J UOEH 25, 185-195. 